\title{
Benjamin Wilke (ed): Stan Allen: Four Projects
}

\author{
Iryna Volynets ${ }^{1}$
}

\begin{abstract}
The geologic surface is more vulnerable and unstable than ever before: we are facing an era when continental shifts, the disappearance of glaciers, the movement of mountains, and earthquakes and tsunamis are creating a new terrestrial crust and new landforms. Changes in geology and earth processes affects our environment as well as our daily life. What is the role of architecture in solving these urgent issues? What is the appropriate way to address these changes? Landform direction in architecture gives insight to an understanding of the environment, mankind's relationship to landscape, and urbanism. The understanding of buildings as a link between people and nature bring even more value to this direction.
\end{abstract}

Keywords Architectural design · Landform architecture - Design concepts · Geometry · Geomorphology · Natural systems

With its sharp angles, facets, and precise geometry, the project has the feel of something highly formal and yet, because it appears to be made by a process which he compares to geological formation, animal herds, plant growth and the like, it signifies Allen's anti-rhetorical rhetoric of form.-Preston Scott Cohen, Postscript "Isosceles, Webs, and Empty Spaces" (Wilke 2017: 156).

The geologic surface is more vulnerable and unstable than ever before: we are facing an era when continental shifts, the disappearance of glaciers, the movement of mountains, and earthquakes and tsunamis are creating a new crust and new landforms on the earth. Changes in geology and earth processes affect our environment as well as our daily life. What is the role of architecture in solving these urgent issues? What is the appropriate way to address these changes?

Iryna Volynets

irvolynets@gmail.com; irena.volynets@gmail.com

1 6a Plugova str., apt.64, Lviv 79059, Ukraine

Birkhäuser 
Landform direction in architecture gives insight to an understanding of the environment, mankind's relationship to landscape, and urbanism. The understanding of buildings as a link between people and nature bring even more value to this direction.

Furthermore, landform architecture is inspired by nature, where the built environment creates a "second nature", a "reconstruction of nature", or becomes a "moving topography". At the beginning of the movement, when the book Landform Building: Architecture's New Terrain (Allen and McQuade 2011) was published, the landform approach was envisioned as a new formal strategy to analyze the relationships between landscape and architecture. This included bringing green surfaces to buildings, replacing the footprint of the building with a continuous park that dissolves into the landscape, and/or establishing a new connection with nature within existing infrastructure. It inspired a new vision of the relationship between nature and architecture. By making a turn towards geological form, landform architecture has created an opportunity to design buildings in response to natural vulnerabilities and disruption of geological surfaces.

The Source Book in Architecture Stan Allen: Four Projects (2017) by Benjamin Wilke is a documentation of discussions with Stan Allen, then a Visiting Professor at the Austin E. Knowlton School of Architecture. For readers, it is a chance to hear Stan's voice, his perspective on architectural practice, education, and revised strategies in design twenty years after his first publication, Field Conditions (Allen 1985). This connection becomes even more interesting when analyzing landform architecture. Landform Building (Allen and McQuade 2011) introduced a new concept of thinking to the architectural world, which opened a huge field of possibilities for further discoveries. Interestingly enough, Wilke's book explains that landform direction extended to formal approaches and tendencies of architectural and urban design. The main metaphor of built environment with natural elements shifts towards the geological transformation of form and architecture (Fig. 1).

The book is organized into six chapters that form an understanding of the geological turn in architecture.

The Introduction, "Geological Form: Towards a Vital Materialism in Architecture", appears to be an extension of the chapter "Form-Artificial Mountains" from Landform Building: Architecture's New Terrain. In the introduction, Allen explains the transition from biological to geological metaphor in architecture. The change was influenced by the process-oriented approach in design, where the buildings are, 'like the ground', capable and flexible enough to adapt to changes in natural systems. The idea of the building as a complex structure with intricate and dynamic messages for the viewer lies in Jane Bennett's concept of 'vital materialism' (2010). The complex geological form of the building (Fig. 2) emphasizes the relationship to the ground, connection to the context, and a new potential of ecology and landscape.

Chapter 2, "Field Conditions Revisited", gives an understanding of the city as a dynamic field that exists on site. Similar to unstable geological conditions, the city is unstable as well. In the densest urban context, the city is envisioned as a field of forces, where the smaller objects create the overall coherence. 


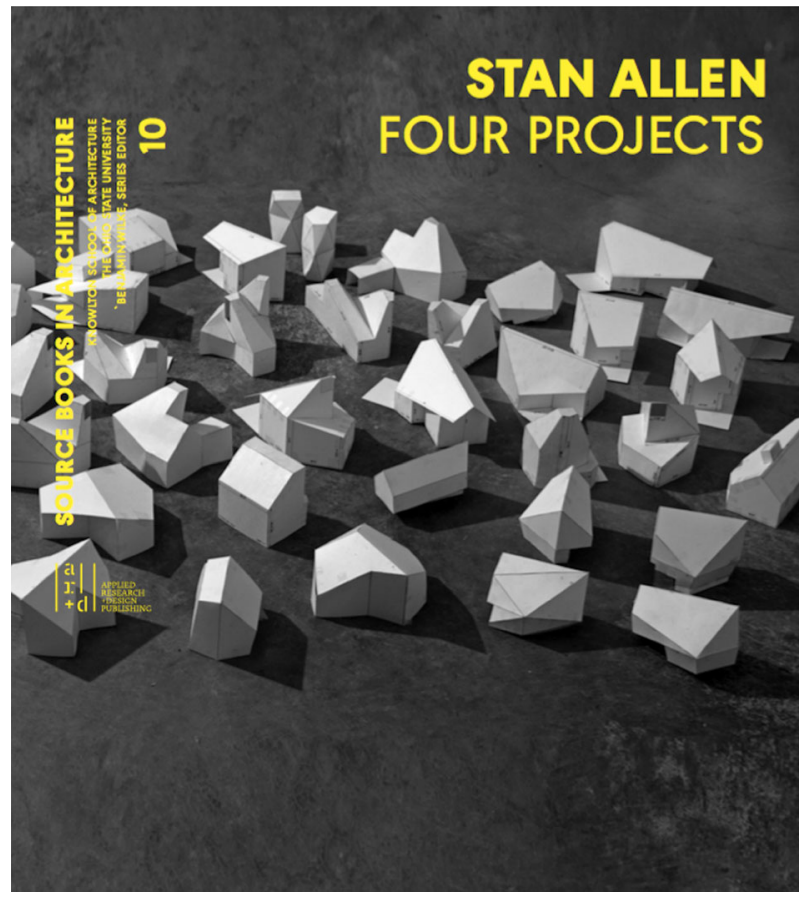

Fig. 1 Cover of Stan Allen: Four Projects (Source Books in Architecture)

Fig. 2 Hudson River Studio, study models

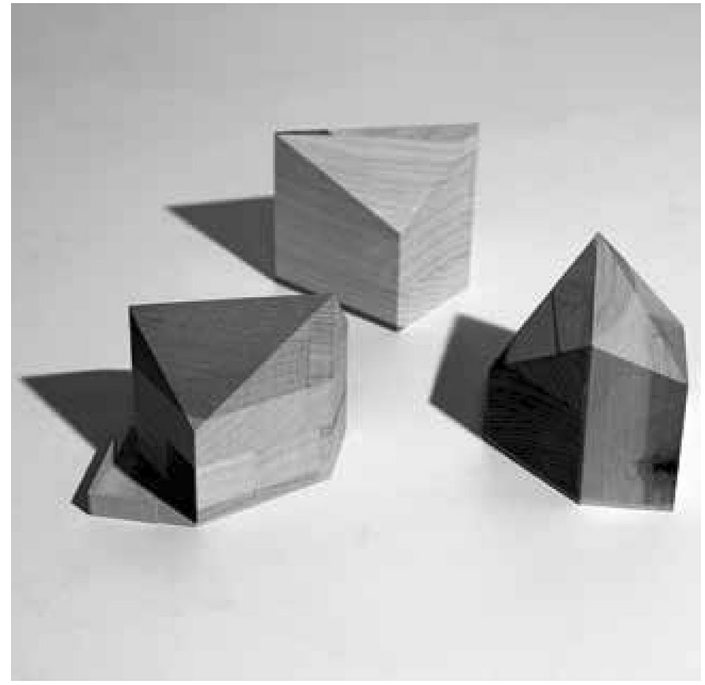

In this discussion, form becomes an important framework that establishes and maintains the balance of individual and collective identity.

“The Chemistry of Imperfect Crystals" by William O'Brien Jr. is a great essay that continues a discussion of architectural form through analyses of Stan's projects 
from large to small scale. The Monument of Freedom and Equality in Liepzig (Fig. 3), an example of a small-scale project, is a series of rocks in the central part of the square, which were once part of a larger boulder (Fig. 4). The author draws a parallel between natural forms and architecture: there is no perfect shape in nature, just as how the chemistry between parts in crystals makes each natural form unique; likewise in architecture, the imperfect forms amplify the role of external forces of the city.

Chapter 3, "Architecture Part for Part", is an open thought, revised design strategy, which resulted from the Maribor Art Gallery Design competition. The shift from part-to-whole to part-to-part in design process was influenced by a desire to make architectural objects more adaptable to changing circumstances. The selfsimilar architectural modules (Fig. 5) behave like a landscape; they are open, independent units, which create a new cohesive whole when merged together. These thoughts provoke changes in form: from curvilinear to facets, and pentagonal geometry of individual modules.

The pentagon is unsettled geometry; when you aggregate pentagons they produce an incomplete rotational pattern (Stan Allen 2017: 37).

In the Maribor Design project pentagons have been used in two main elements: the plan dimension and the iconic profile of the roofline.

Chapter 4, "The Agency of the Plan", is a five-argument essay centered on the reasons why architects draw plans and why it matters. This part of the book is especially rich of diagrams and drawings that emphasize the ideas stated earlier in the book. It is interesting to review the logical sequence of selected projects through a historical analysis.

Amongst four selected projects, New Maribor Art Gallery is an amazing example of the geomorphical approach (Fig. 6), in which the strong figural presence of the building establishes a clear identity in the historical area of Maribor city. The project manifests the idea of open, in-between spaces that behave like landscapes and are capable of responding to changing circumstances of use and building program. The logic of the five-sided plan transformation is clearly explained via

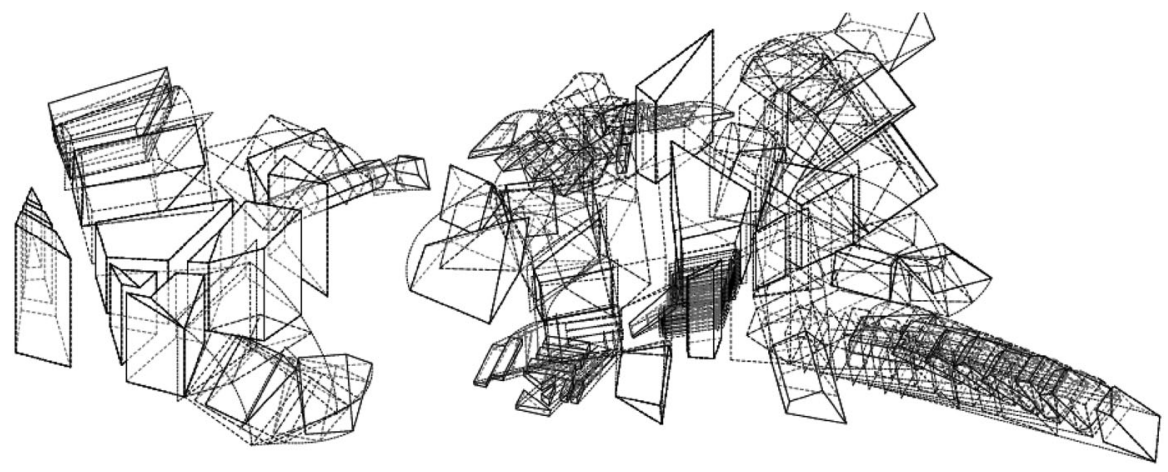

Fig. 3 Stan Allen Architect, monument to freedom and equality, Leipzig, Germany, 2012, cutting diagram 


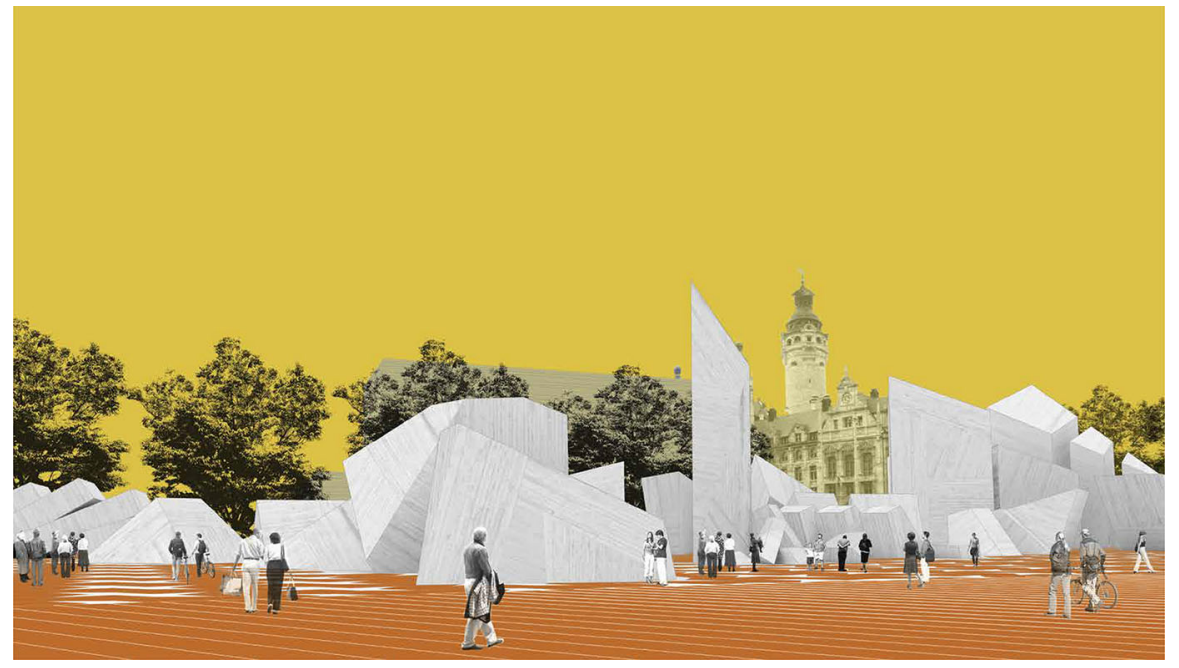

Fig. 4 Monument to freedom and equality, perspective

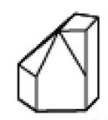

1 UNIT
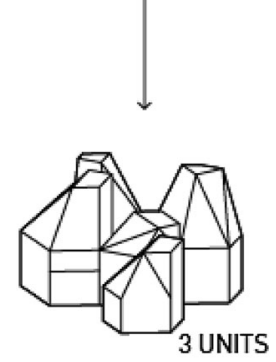
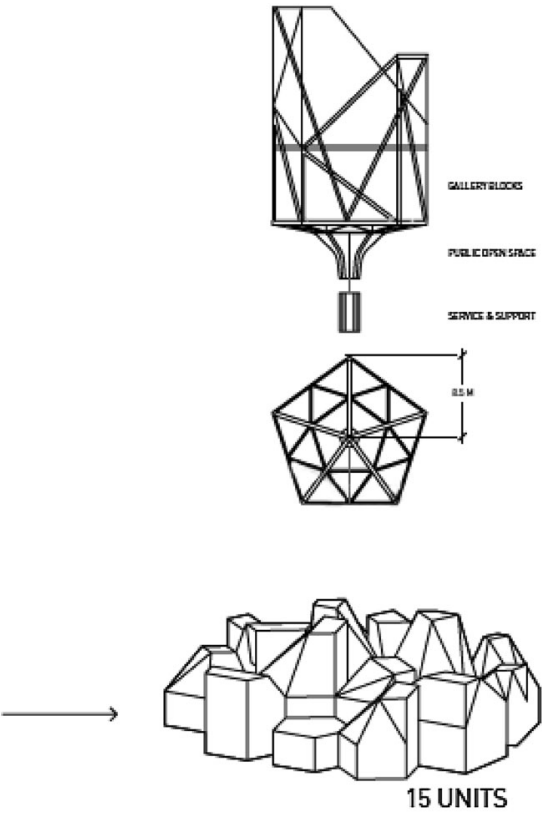

Fig. 5 New Marribor Art Gallery, part to whole diagram

form generation diagrams, plans of extrusion, and unfolded schemes of a building structure (Figs. 7, 8). Although the book has a selection of projects that explain the logic of form creation, it says very little about social factors such as interaction between buildings and people. With an emphasis on form, the architecture loses its connection to nature. 
Fig. 6 New Marribor Art

Gallery, model in context

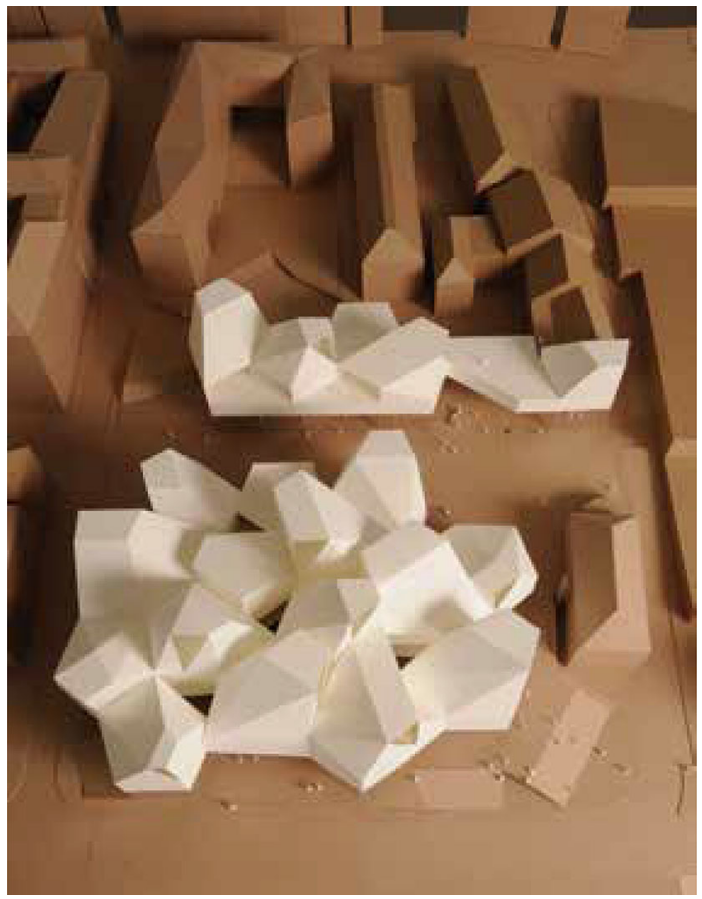

Fig. 7 Axonometric structural drawing

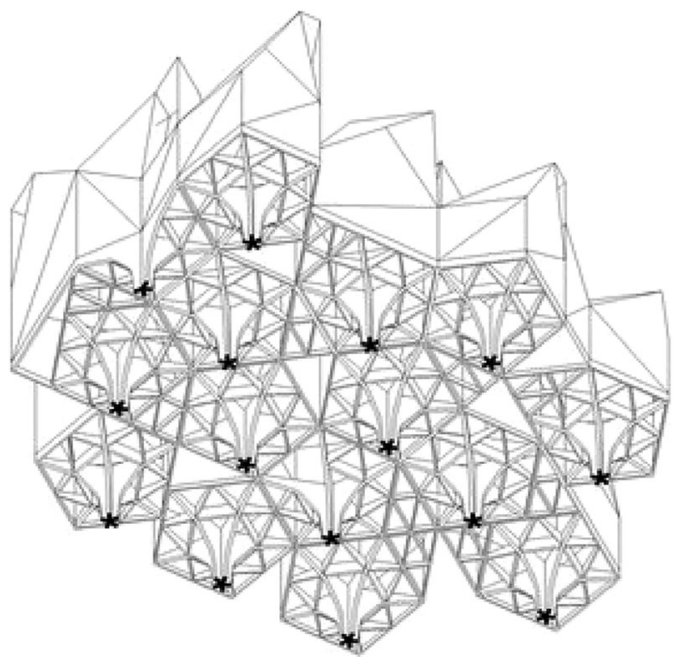

In Allen's first book in landform direction, Landform Building: Architecture's New Terrain (Allen and McQuade 2011) many professional practitioners expected to find a book of guidelines and direct recommendations on how to design buildings that can imitate nature-like forms. Over the last five years, it's been a struggle to find even a hint of how to design landform buildings. In The Geological Turn, Allen 


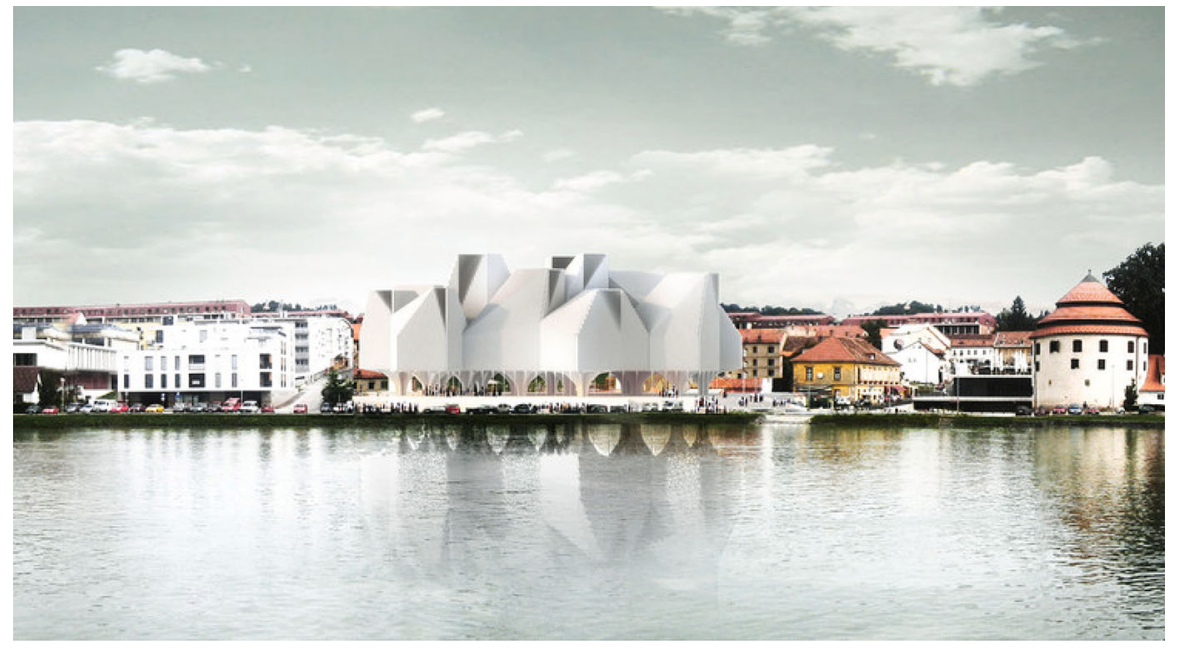

Fig. 8 New Marribor Art Gallery, River Drava view

argues that he is 'skeptical of the idea of a set of ready-made rules that might be applied a-priori' (2017: 61). The mystery of generating an exceptional formal solution is sometimes unexplainable, which is similar to the mystery of processes in natural systems. One can try to recreate such processes and turn towards geological form, but it is unknown how users will respond to these buildings over time.

There is a growing interest in landform architecture. Nowadays, the discipline is moving forward quickly, as there are new challenges that architecture is being asked to solve. By turning towards geological form, architects are accepting a strong figural identity of geometrical form that is more resilient to time and changing conditions. Going beyond the formal strategies proposed by landform architecture, there is an urgent need to understand the role of humans in the place of their inhabitation.

The cultural awareness of geological and social factors creates an opportunity to shape the built environment. It is also essential to understand that human forces have the same impact as natural forces, and that humans themselves are positioned as the main actors in the process of shaping the environment.

Benjamin Wilkes's Stan Allen: Four Projects is a welcome extension of previous manifestations of forms and ideas in architecture, in which the role of an architect is strictly defined. The buildings are no longer self-identical structures that simply exist in their context, but rather they are defined by urban context, nature, roads, trees, and the human beings who inhabit and use them. The geological forms and geomorphical approach are responding to the main challenges of the anthropocene era by making an influence on people via architecture.

The book is highly recommended for architects, students, researchers, and as a source of inspiration for interdisciplinary investigation. There is an urgent need to create more Source Books to continue exploring landform architecture in different directions. 
Acknowledgements All images reproduced by kind permission of Applied Research + Design Publishing, San Francisco.

\section{References}

Allen, Stan. 1985. Field Conditions. In: Points + Lines (New York: Princeton Architectural Press).

Allen, S., and Marc McQuade. (2011), Landform building: Architecture's New Terrain (Baden: Schirmer/ Mosel).

Bennett, J. (2010), Vibrant matter: a political ecology of things (Durham: Duke University Press).

Wilke, Benjamin, ed. 2017. Stan Allen: Four Projects. Source Books in Architecture 10 (San Francisco: Applied Research \& Design). ISBN 9781939621337.

Iryna Volynets is the principal of Volynets architectural bureau in Lviv, Ukraine and a Ph.D. student in the Department of Architecture at the Lviv Polytechnic National University. In research and practice, Volynets works at the intersection of building and landscape with a focus on the potential of landform architecture to engage topography, territory, and urban ecosystems. She is part of the design team for Villa Jenny, a multifamily residential development with landform integration, currently under construction in Osoyro, Norway. Her work in landform design was recognized by the magazine Forbes. Ukraine (December 2014) for its potential to influence the future of Ukrainian cities. Volynets was a Visiting Fulbright Scholar in the Department of Architecture at the University of Oregon, USA (2015-2016) where she produced the volume Landform [in] Architecture, an exploration of natural landforms, the way they are created, and how they change over time. 